\title{
Hopelessness and perceived stress: the mediating role of cognitive flexibility and intolerance of uncertainty
}

\author{
Ayse Sibel Demirtas $^{10}$, Banu Yildiz ${ }^{10}$ \\ ${ }^{1}$ Alanya Alaaddin Keykubat University, Faculty of Education, Department of Guidance and Psychological Counseling, Antalya - Turkey
}

\begin{abstract}
Objective: This study aims to explore the relationships among hopelessness, cognitive flexibility, intolerance of uncertainty, and perceived stress in a non-clinical sample by proposing a multiple mediation model. It was suggested that hopeless individuals have low cognitive flexibility and high intolerance of uncertainty; consequently, they are more likely to perceive stress.
\end{abstract}

Method: The participants of this study comprised 302 university students (46.7\% female and $53.3 \%$ male) between 18 and 40 years of age who were recruited from a state university in Turkey. To collect data, Beck Hopelessness Scale, Cognitive Flexibility Inventory, Intolerance of Uncertainty Scale, and Perceived Stress Scale were applied.

Results: The results showed that hopelessness is negatively correlated with cognitive flexibility and positively correlated with intolerance of uncertainty and perceived stress. Cognitive flexibility has been found to be negatively correlated with intolerance of uncertainty and perceived stress. There is also a positive correlation between intolerance of uncertainty and perceived stress. The mediation of cognitive flexibility and intolerance of uncertainty in the relationship between hopelessness and perceived stress is also statistically significant in the model, and all variables explain approximately $37.0 \%$ of the variance in perceived stress. Conclusion: The findings of the study are considered to provide a guide for mental health professionals and researchers. Keywords: Cognitive flexibility, hopelessness, intolerance of uncertainty, perceived stress

\section{INTRODUCTION}

Stress is a universal concept that has been studied in various fields of psychology for a long time. Perceived stress has been defined as "the extent to which people found their lives unpredictable, uncontrollable, and overloading" (1). A literature review shows that perceived stress has negative effects on the cognitive, emotional, social, and physical functioning of affected individuals $(2,3)$. Considerable evidence gathered in samples of university students suggests that perceived stress is associated with coping resources, college belonging, social support satisfaction, emotional intelligence, gender role identity, and self-compassion (4-9).

As has been previously reported in the literature, hopelessness is one of the most common risk factors for stress and depression $(10,11)$. Hopelessness, a cognitive disorder, may develop when the people realize that their expectations and conditions may lead to future negative consequences (12). Abramson et al. (13) conceptualized hopelessness as "the two core elements of this proximal sufficient cause: (a) negative expectations about the occurrence of highly valued outcomes (a negative outcome expectancy), and (b) expectations of

How to cite this article: Demirtas AS, Yildiz B. Hopelessness and perceived stress: the mediating role of cognitive flexibility and intolerance of uncertainty. Dusunen Adam The Journal of Psychiatry and Neurological Sciences 2019;32:259-267.

Correspondence: Ayse Sibel Demirtas, Alanya Alaaddin Keykubat University, Faculty of Education, Department of Guidance and Psychological Counseling, Antalya - Turkey

Phone: +90 24251060 60/30 40 E-mail: sibel.demirtas@alanya.edu.tr

Received: March 28, 2019; Revised: May 22, 2019; Accepted: July 06, 2019 
helplessness about changing the likelihood of occurrence of these outcomes (a helplessness expectancy)". O'Connor and Sheehy (14) conceptualized hopelessness as the degree of an individual's pessimistic expectations about the future. Research has provided evidence for hopelessness being an important predictor of negative consequences in mental health. For instance, Kleiman et al. (15) found in a sample of college students that depression symptoms mediated the relationship between hopelessness and negative dependent events. Williams et al. (10) examined the role of hopelessness in students seeking treatment at a university counseling center, reporting that stress was one of the most commonly recognized concerns. Dixon et al. (11) also found significant associations between hopelessness, stress, and depression scores in college students.

Based on prior studies, it has been suggested that cognitive flexibility may explain the association between hopelessness and perceived stress in current research. Although there is a lack of agreement within the literature about the definition and measurement of this construct, in most operational definitions the main constituent of cognitive flexibility is "the ability to switch cognitive sets to adapt to the changing environmental stimuli" (16). According to Martin et al. (17) cognitive flexibility is individuals' ability to be aware of options, adapt to different and new situations, and feel competent in these situations. Canas et al. (18) defined cognitive flexibility as the ability to manipulate information-processing strategies to meet new and unexpected situations in the environment. Individuals with a high level of cognitive flexibility are flexible and self-confident, aware of their options in communication and problem situations, and are sociable, sensitive, and tolerant to conflict and uncertainty $(17,19,20)$. Consistent with this point of view, cognitive flexibility has a positive effect on the potential for coping with internal and external stressors (21). Gabrys et al. (22) found a high level of correlation between cognitive flexibility scores and negative stress assessments including greater perceived threats and uncontrollability. Cognitive control and flexibility are involved in emotion regulation in addition to facilitating task-oriented behaviors, and a lack of these skills plays a critical role in mental health $(22,23)$. A high level of cognitive flexibility has been associated with a significant decrease in emotional stress using cognitive reappraisal and constructive thinking (24).

Although the literature review shows that there is very limited research to support a direct link between hopelessness and cognitive flexibility, we suggest, based on the conceptualizations of the constructs $(14,17)$, that hopelessness is negatively associated with cognitive flexibility, as generalized negative outcome expectancies stemming from hopelessness decrease individuals' awareness of the available cognitive alternatives and their ability to control disturbing feelings. There is also some evidence to suggest that cognitive flexibility is implicated in hopelessness (25). For example, diathesisstress-hopelessness model by Schotte et al. (26) operationally defines poor problem solving skills as an individual's failure to generate solutions to interpersonal problems they encounter. Valderrama (27) suggests that cognitive inflexibility may lead to responses to stress that involve difficulty disengaging from negative moods, rather than attempting to generate solutions to problems.

Another variable that constitutes a powerful stressor is intolerance of uncertainty (28) having been conceptualized as "a dispositional characteristic that results from a set of negative beliefs about uncertainty and its implications and involves the tendency to react negatively on an emotional, cognitive, and behavioral level to uncertain situations and events" (29). In a sample of 1092 young adults, Zlomke et al. (30) found that intolerance of uncertainty served to moderate between daily stress and worry. In a similar study using a sample of individuals with a history of trauma, intolerance of uncertainty was found to moderate the relation between worry and posttraumatic stress symptoms (31). Prior research suggests that intolerance of uncertainty plays an important role in comprehending worry and its maintenance (32). Individuals who cannot tolerate uncertainty believe that they do not have efficacious coping skills to deal with threatening conditions that potentially create trouble and negative feelings (33).

In the current study, we also hypothesized that intolerance of uncertainty is associated with greater hopelessness and lower cognitive flexibility. Individuals with high intolerance of uncertainty have cognitive bias that leads them to perceive uncertain situations as threatening and uncomfortable (34). This form of thinking appears to be related to individuals' pessimistic expectations about the future. A study by Yanar (35), carried out in a sample of patients and their relatives in the context of organ transplantation confirmed a positive relationship between hopelessness and intolerance of uncertainty in both groups. Intolerance of uncertainty is also linked to cognitive inflexibility that affects people's perceptions, interpretations, and 
responses to certain situations (36). A recent study by Lieberman et al. (37) demonstrated that cognitive flexibility in a sample of adults diagnosed with panic disorder negatively correlated with intolerance of uncertainty. Ozturk (38) also reported that cognitive flexibility was negatively correlated with intolerance of uncertainty in a sample of university students. Cognitively inflexible individuals lack the ability to control disturbing thoughts and emotions and to think about and handle different views in multiple ways $(16,22)$. These characteristics are considered to block a positive reaction to uncertain situations and events.

Based on the explanations given above, the current study was designed to examine the relationships among hopelessness, cognitive flexibility, intolerance of uncertainty, and perceived stress in university students by proposing a multiple mediation model. We supposed that hopeless individuals have low cognitive flexibility, high intolerance of uncertainty, and consequently are more likely to perceive stress. To our knowledge, there is no research considering the interactions of these variables together. Thus, this study aims to provide useful insight for further research by experts working within the field (Figure 1).

\section{METHOD}

\section{Research Design}

In this study, a correlational research design was used. The relationships among hopelessness (predictor variable), cognitive flexibility (first mediator), intolerance of uncertainty (second mediator), and perceived stress (outcome variable) were examined through mediation analysis.

\section{Participants and Procedure}

A convenience sample of 302 university students enrolled in a teacher training program at a small state university in the south of Turkey (46.7\% female, $53.3 \%$ male) was used in the study. Based on the convenience sampling method (39), the data collection process

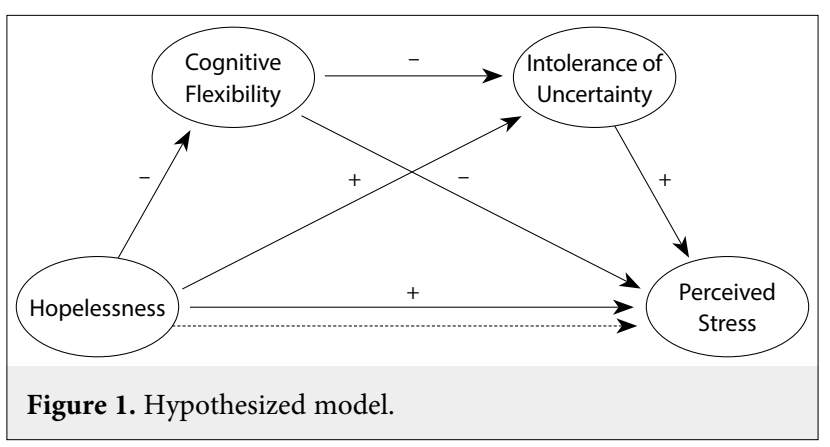

continued until a sufficient number was reached. Data collection took about 1 week. While 302 participants filled in the measurement tools, 9 participants were excluded from the study because their data were found to be incomplete. Thus, the analyses were conducted with 293 data sets. In accordance with the ethical principles for research with students, permission was obtained from the University Research Ethics Committee. The measurement tools were administered in classroom settings by researchers receiving informed consent. All the students participated in the research voluntarily (without being given extra credit or compensation). The gathering of the data took approximately 20 minutes. The data were collected during the second term (summer) of the academic year 2017-2018.

\section{Measures}

Beck Hopelessness Scale (BHS): The BHS was developed by Beck et al. (12) to measure the degree of individuals' hopelessness. The scale consists of 20 items, 9 positively and 11 negatively phrased, answered in "Yes-No" fashion. The adaptation of the Turkish version was carried out by Seber et al. (40). In the validity study, the BHS was found to differentiate between patient and non-patient groups. In the criterion validity study, a significant relationship was found between BHS and Beck Depression Inventory $(\mathrm{r}=0.65)$. Cronbach's alpha coefficient for the whole scale was calculated to be 0.86 . The test-retest reliability of the scale was found to be 0.74 . In the study by Durak et al. (41) on the validity and reliability of the BHS, the findings of the exploratory factor analyses revealed that the BHS had a three-factor structure: 1) "feelings about the future," 2) "loss of motivation," and 3) "future expectations". Cronbach's alpha reliability coefficients were calculated between 0.72 and 0.78 for the subdimensions. In our study, Cronbach's alpha coefficient for the total scale was 0.80 .

Cognitive Flexibility Inventory (CFI): The CFI, developed by Dennis et al. (16). The inventory was designed to measure three aspects of cognitive flexibility: “(a) the tendency to perceive difficult situations as controllable; (b) the ability to perceive multiple alternative explanations for life occurrences and human behavior; and (c) the ability to generate multiple alternative solutions to difficult situations". The reliability and validity study for the scale in Turkish culture was carried out by Gulum et al. (42). Exploratory factor analysis showed that the two-factor structure of the scale has the same psychometric properties as its 
original form. Cronbach's alpha coefficients were found to be 0.89 for alternatives, 0.85 for control, and 0.90 for total. In addition, confirmatory factor analysis in the validity study by Dogan-Lacin (43) showed that the scale has an acceptable fit. In the current study, the total score was obtained and used. Cronbach's alpha coefficient was calculated to be 0.91 .

Intolerance of Uncertainty Scale (IUS): The original form of the IUS developed by Freeston et al. (44) was adapted by Buhr et al. (32). Cronbach's alpha coefficient of the scale was calculated to be 0.94 , and the test-retest reliability was 0.74 . The scale was adapted into Turkish by Sari et al. (45). It consists of 26 items and 4 sub-dimensions, namely, "uncertainty is stressful and distressing," "negative self-assessment about uncertainty," "disturbing thoughts about the uncertainty of future," and "uncertainty keeps someone from acting." Cronbach's alpha coefficient of the scale was calculated to be 0.93 and the test-retest reliability was 0.66 . In the current study, the total score was obtained and used. Cronbach's alpha coefficient was calculated to be 0.93 .

Perceived Stress Scale (PSS): The PSS was developed by Cohen et al. (1) to determine the stress levels perceived by individuals. The instrument consists of 10 items answered in the form of 5-point Likert-type scales $(1=$ Never, $5=$ Very frequent). Higher scores indicate higher perceived stress levels. PSS was adapted to Turkish culture by Yerlikaya et al. (46). A significant relationship was found between PSS and Beck Depression Inventory and State-Trait Anxiety. Cronbach's alpha coefficient was calculated to be 0.84 . In the current research, Cronbach's alpha coefficient was 0.80 .

\section{Statistical Analysis}

Descriptive statistics, Pearson's correlation method, an approach based on ordinary least squares regression, and bootstrapping were used to analyse the data. Mahalanobis distance values were calculated in order to determine outliers, indicating that there were no extreme values in the data set that would negatively affect the analyses. The values of kurtosis and skewness were calculated to prove normal univariate distribution. As the values of skewness and kurtosis showed acceptable ranges in the region of -1.5 to +1.5 (Table 1 ), it was concluded that the data were normally distributed (47).

A multiple mediation model, which involves "simultaneous mediation by multiple variables" (48), was also used in the present study to evaluate the mediating roles of cognitive flexibility and intolerance of uncertainty between hopelessness and perceived stress. Studying mediation "help[s] understand the mechanisms, pathways, and intermediates whereby a cause affects an outcome" (49). According to Hayes (50), if zero is not included in the $95.0 \% \mathrm{CI}$, we can conclude with $95.0 \%$ certainty that the indirect effect is significantly different from zero, $\mathrm{p}<0.05$ (two-tailed). In addition, a contrast test was used to determine specific indirect effects of the variables and stronger mediators in the model. Bootstrapping analyses of the study were conducted by "Multiple Mediation Model 6" with PROCESS Macro 3 using IBM SPSS 24.0 (51). A p-value of 0.05 was considered the limit of statistical significance.

\section{RESULTS}

\section{Descriptives and Correlations}

Pearson's correlation coefficients were utilized to determine the relationships among hopelessness, cognitive flexibility, intolerance of uncertainty, and perceived stress. The means, standard deviations, and correlations are presented in Table 1.

Table 1 shows that hopelessness is negatively correlated with cognitive flexibility $(\mathrm{r}=-0.39, \mathrm{p}<0.01)$ and positively correlated with intolerance of uncertainty and perceived stress, respectively $(\mathrm{r}=0.27$ and 0.39 , $\mathrm{p}<0.01$ ). Cognitive flexibility is negatively correlated with intolerance of uncertainty and perceived stress. There is also a positive correlation between intolerance of uncertainty and perceived stress.

\section{Mediation Model Analysis}

The findings for the serial mediating roles of cognitive flexibility and intolerance of uncertainty in the

Table 1: Correlation analysis among hopelessness, cognitive flexibility, intolerance of uncertainty, and perceived stress

\begin{tabular}{|c|c|c|c|c|c|c|c|c|}
\hline Variables & Mean & SD & Kurtosis & Skewness & 1 & 2 & 3 & 4 \\
\hline 1. Hopelessness & 4.92 & 3.87 & 0.77 & 1.17 & --- & & & \\
\hline 2. Cognitive flexibility & 90.87 & 15.47 & -0.20 & -0.39 & $-0.39^{*}$ & --- & & \\
\hline 3. Intolerance of uncertainty & 81.00 & 20.50 & -0.47 & -0.09 & $0.27^{*}$ & $-0.23^{*}$ & --- & \\
\hline 4. Perceived stress & 30.75 & 6.56 & 0.09 & 0.17 & $0.39^{*}$ & $-0.39^{*}$ & $0.48^{*}$ & -- \\
\hline
\end{tabular}

Pearson's Correlation was used. * $p<0.01$, SD: Standard deviation 


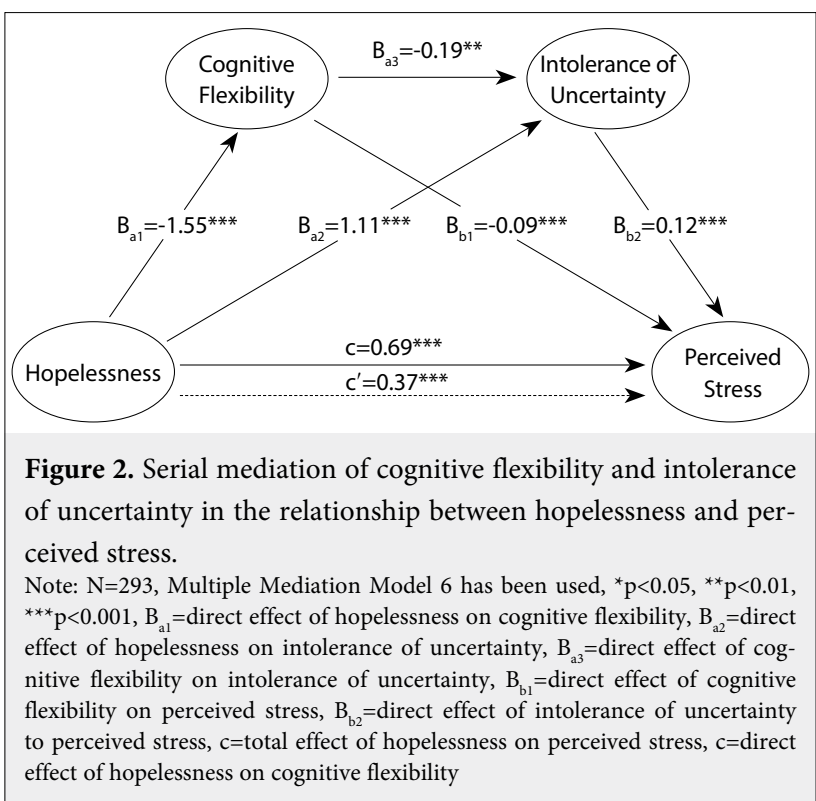

relationship between hopelessness and perceived stress are presented in Figure 2.

As presented in Figure 2, the total effect of hopelessness on perceived stress is statistically significant $(\mathrm{c}=0.69, \mathrm{SE}=0.09, \mathrm{t}=7.65, \mathrm{p}<0.001)$ (step 1). The direct effects of hopelessness on cognitive flexibility $(\mathrm{B}=-1.55, \mathrm{SE}=0.21, \mathrm{t}=-7.23, \mathrm{p}<0.001)$ and intolerance of uncertainty $(\mathrm{B}=1.11, \mathrm{SE}=0.31, \mathrm{t}=3.51, \mathrm{p}<0.001)$ are statistically significant, as is the direct effect of cognitive flexibility (the first mediating variable) on intolerance of uncertainty (the second mediating variable) $(\mathrm{B}=-$ $0.19, \mathrm{SE}=0.07, \mathrm{t}=-2.50, \mathrm{p}<0.01$ ) (step 2). In addition, the direct effects of cognitive flexibility $(B=-0.09, S E=0.02$, $\mathrm{t}=-4.13, \mathrm{p}<0.001)$ and intolerance of uncertainty
$(\mathrm{B}=0.12, \mathrm{SE}=0.01, \mathrm{t}=7.88, \mathrm{p}<0.001)$ on perceived stress are also significant (step 3). When hopelessness and two mediating variables were entered simultaneously into the model (step 4), the significance of the relationship between hopelessness and perceived stress decreased, but the significance level did not change $\left(c^{\prime}=0.37\right.$, $\mathrm{SE}=0.08, \mathrm{t}=4.24, \mathrm{p}<0.001)$. These results support the mediational hypothesis. The model is significant $\left(\mathrm{F}_{(5}\right.$ 276), $\mathrm{p}<0.001)$ and explains approximately $37.0 \%$ of the variance in perceived stress.

\section{Indirect Effects of Hopelessness on Perceived Stress through Cognitive Flexibility and Intolerance of Uncertainty}

A comparison of the direct and specific indirect effects of participants' hopelessness on perceived stress through cognitive flexibility and intolerance of uncertainty is presented in Table 2 .

The indirect effects were tested using bootstrapping with 10,000 bootstrap samples. The estimates were taken within $95.0 \%$ confidence intervals, and the biascorrected and accelerated results are presented in Table 2. Because of the unequal distribution of men and women in the sample, gender was used as a covariate in the analyses. The total indirect effect (the difference between the total and direct effects /c-c') of hopelessness through cognitive flexibility and intolerance of uncertainty were statistically significant (point estimate $=0.3209$ and $95.0 \%$ BCa CI [0.2190, $0.4327])$. In addition, mediators in the hypothesized model were examined individually. The results revealed that the mediation of cognitive flexibility (point estimate $=0.1411$ and $95.0 \%$ BCa CI [0.0704,

Table 2: Comparison of direct and specific indirect effects of hopelessness on perceived stress through cognitive flexibility and intolerance of uncertainty

\begin{tabular}{|c|c|c|c|c|}
\hline \multirow[b]{3}{*}{ Effects } & \multirow[b]{2}{*}{ Product of coefficients } & \multicolumn{3}{|c|}{ Bootstrapping } \\
\hline & & $95 \%$ & $\mathrm{BCa}$ & Confidence interval \\
\hline & Point estimate & SE & Lower & Upper \\
\hline Total indirect effects & 0.3209 & 0.0552 & 0.2190 & 0.4327 \\
\hline $\mathrm{H} \rightarrow \mathrm{CF} \rightarrow \mathrm{PS}$ & 0.1411 & 0.0405 & 0.0704 & 0.2285 \\
\hline $\mathrm{H} \rightarrow \mathrm{IU} \rightarrow \mathrm{PS}$ & 0.1406 & 0.0419 & 0.0633 & 0.2266 \\
\hline $\mathrm{H} \rightarrow \mathrm{CF} \rightarrow \mathrm{IU} \rightarrow \mathrm{PS}$ & 0.0392 & 0.0183 & 0.0079 & 0.0796 \\
\hline \multicolumn{5}{|l|}{ Contrasts } \\
\hline Model 1 versus model 2 & 0.0005 & 0.0632 & -0.1187 & 0.1308 \\
\hline Model 1 versus model 3 & 0.1020 & 0.0402 & 0.0298 & 0.1864 \\
\hline Model 2 versus model 3 & 0.1015 & 0.0503 & 0.0035 & 0.2005 \\
\hline
\end{tabular}

Note: $\mathrm{N}=293, \mathrm{k}=10.000,{ }^{*} \mathrm{p}<0.05,{ }^{* *} \mathrm{p}<0.01,{ }^{* * *} \mathrm{p}<0.001$, Control Variables: Gender, Grade, BCa: Bias corrected and accelerated 10.000 bootstrap samples, $\mathrm{H}$ : Hopelessness, CF: Cognitive flexibility, PS: Perceived stress, IU: Intolerance of uncertainty Model 1=Hopelessness-Cognitive Flexibility-Perceived Stress (p<0.001), Model 2=Hopelessness-Intolerance of Uncertainty-Perceived Stress $(p<0.001)$, Model $3=$ Hopelessness-Cognitive Flexibility-Intolerance of Uncertainty-Perceived Stress $(p<0.001)$. Model 1 versus Model $2(p>0.05)$, Model 1 versus Model $3(p<0.001)$, Model 2 versus Model $3(p<0.001)$ 
$0.2285])$, the mediation of intolerance of uncertainty (point estimate $=0.1406$ and $95.0 \%$ BCa CI [0.0633, $0.2266]$ ), and the multiple mediation of cognitive flexibility and intolerance of uncertainty (point estimate $=0.0392$ and $95.0 \%$ BCa CI $[0.0079,0.0796])$ were also statistically significant.

Finally, the strengths of individual indirect effects against each other were compared. In the first comparison, model 1 (mediation of cognitive flexibility) was not statistically different from model 2 (mediation of adjustment). Based on a $95.0 \%$ BCa confidence interval, within the statistically significant comparison, in the second comparison, model 1 (mediation of cognitive flexibility) was statistically different from model 3 (serial multiple mediation of cognitive flexibility and intolerance of uncertainty), and model 2 (mediation of intolerance of uncertainty) was stronger than model 3 (serial multiple mediation of cognitive flexibility and intolerance of uncertainty). The indirect effect via cognitive flexibility is greater than the effect via the two other indirect effects.

\section{DISCUSSION}

Our findings showed that the mediation of cognitive flexibility and intolerance of uncertainty in association between hopelessness and perceived stress is statistically significant in the model. Also, the hypothesized mediational model reaches relevant levels of significance and explains approximately $37.0 \%$ of the variance in perceived stress. The findings of the model comparisons also revealed that the mediation of cognitive flexibility is stronger than the mediation of intolerance of uncertainty and serial multiple mediation of cognitive flexibility and intolerance of uncertainty.

In line with previous research, the findings of this study propose that hopelessness is an important construct in understanding perceived stress $(52,53)$. In the related literature, hopelessness is discussed conceptually from different theoretical perspectives $(12,14,54)$. The common point of these definitions is that hopelessness entails negative and pessimistic expectations for the future. Hopelessness is connected with a broad range of negative mood states, both in clinical and non-clinical samples (55). Hopeless individuals have negative outcomes and helplessness expectancy that keep them from achieving a desired outcome (13). Consistent with this notion, Dhanalakshmi (56) reported that hopelessness emerged to an important predictor of perceived stress in college students. In a study by Heisel et al. (57) suicide ideation was found to be associated significantly with daily stress, depression, general hopelessness, and social hopelessness.

In the current research, as we had expected, hopelessness is negatively correlated with cognitive flexibility. Thinking negatively discourages hopeless individuals from perceiving difficult situations as controllable, to think more broadly and generate multiple alternative solutions to difficult situations. According to Snyder et al. (58) high-hope people accept self-talk agentic phrases such as "I can do this" and "I am not going to be stopped". Based on these explanations, hopeful individuals are predicted to have high cognitive flexibility in order to achieve their goals. On the other hand, hopeless individuals have expectations that there will be no positive results in the future, while negative events will occur. Because of a cognitive style of negative expectation, hopelessness is connected with cognitive rigidity.

The results also demonstrated that hopelessness is positively correlated with intolerance of uncertainty, which in turn is associated with cognitive bias that causes the perception of uncertain situations as threatening and uncomfortable (34). The cognitive bias of an individual with high intolerance of uncertainty appears to be linked to negative outcome expectancies of hopelessness. This finding is consistent with a study finding a positive association between hopelessness and intolerance of uncertainty (35).

Low cognitive flexibility has been found to be related with perceived stress, which is in line with our hypothesis. Individuals with low levels of cognitive flexibility cannot use cognitive restructuring in reducing emotional stress in the way that cognitively flexible individuals do. Due to their lack of cognitive flexibility, individuals with high levels of intolerance of uncertainty may tend to be confused by worrying thoughts and feelings. Our findings are consistent with studies in which intolerance of uncertainty and low cognitive flexibility are associated with negative mood states $(44,59,60)$. Greco et al. (28) suggested that the prospect of facing an unknown, potentially threatening situation is more stressful to some individuals than to others.

The present results also reveal that cognitive flexibility is negatively correlated with intolerance of uncertainty. Consistent with our findings, Ozturk (38) reported that cognitive flexibility negatively correlated with intolerance of uncertainty in a sample of university students. A recent study by Lieberman et al. (37) also 
demonstrated that cognitive flexibility was negatively associated to intolerance of uncertainty in a sample of adults diagnosed with panic disorder. Intolerance of uncertainty is associated with cognitive bias that affects people's perceptions, interpretations, and responses to certain situations (36). Our findings appear to suggest that cognitive flexibility is an important characteristic that helps individuals to cope competently with ambiguous situations. Under stressful conditions, cognitive flexibility will reduce the intolerance of uncertainty and perceived stress level.

Consistent with prior research, our study found intolerance of uncertainty to be associated with perceived stress. In a sample of 1092 young adults, Zlomke et al. (30) found that intolerance of uncertainty positively correlated with stress and worry. Counsell et al. (61) also reported that intolerance of uncertainty was associated with social and generalized anxiety disorder. Lally et al. (62) found a positive relationship between psychological distress and a higher intolerance of uncertainty in a sample of medical students. The link between uncertainty and stress theoretically suggests that intolerance of uncertainty could increase the negative impact of stressors (63).

Although this research reached its aims, there is a limitation regarding the participants, as they were chosen by convenience sampling method. Another limitation of our research is the cross-sectional nature of the data, as no causality can be determined. In future research, longitudinal and experimental studies are needed to investigate complex causal relationships. Notwithstanding these limitations, this study provides an understanding of the link between hopelessness and perceived stress by investigating the mediating roles of cognitive flexibility and intolerance of uncertainty. The findings obtained from this study are considered to provide awareness for mental health professionals and researchers.

\begin{tabular}{|c|c|c|}
\hline \multicolumn{2}{|c|}{ Contribution Categories } & \multirow{2}{*}{\begin{tabular}{|l} 
Author Initials \\
A.S.D., B.Y.
\end{tabular}} \\
\hline \multirow{3}{*}{ Category 1} & Concept/Design & \\
\hline & Data acquisition & A.S.D., B.Y. \\
\hline & Data analysis/Interpretation & A.S.D., B.Y. \\
\hline \multirow{2}{*}{ Category 2} & Drafting manuscript & A.S.D., B.Y. \\
\hline & Critical revision of manuscript & A.S.D., B.Y. \\
\hline Category 3 & Final approval and accountability & A.S.D., B.Y. \\
\hline \multirow{2}{*}{ Other } & Technical or material support & A.S.D. \\
\hline & Supervision & N/A \\
\hline
\end{tabular}

Ethics Committee Approval: This study was approved by the ethics committee of Alanya Alaaddin Keykubat University.
Informed Consent: Written informed consent was obtained from the participants.

Peer-review: Externally peer-reviewed.

Conflict of Interest: No conflict of interest was declared by the authors.

Financial Disclosure: The authors declared that this study has received no financial support.

\section{REFERENCES}

1. Cohen S, Kamarck T, Mermelstein R. A global measure of perceived stress. J Health Soc Behav 1983; 24:385-396.[CrossRef]

2. Pechtel P, Pizzagalli, D. Effects of early life stress on cognitive and affective function: an integrated review of human literature. Psychopharmacology (Berl) 2011; 214:55-70. [CrossRef]

3. McEwen BS, Gianaros PJ. Stress- and allostasis-induced brain plasticity. Annu Rev Med 2011; 62:431-445. [CrossRef]

4. Matheny KB, Curlette WL, Aysan F, Herrington A, Gfroerer CC, Thompson D, Hamarat E. Coping resources, perceived stress, and life satisfaction among Turkish and American university students. Int J Stress Manag 2002; 9:81-97. [CrossRef]

5. Civitci A. Perceived stress and life satisfaction in college students: belonging and extracurricular participation as moderators. Procedia Soc Behav Sci 2015; 205:271-281. [CrossRef]

6. Crutcher B, Moran RN, Covassin T. Examining the relationship between social support satisfaction and perceived stress and depression in athletic training students. Athletic Training Education Journal 2018; 13:168-174. [CrossRef]

7. Ranasinghe $\mathrm{P}$, Wathurapatha WS, Mathangasinghe $\mathrm{Y}$, Ponnamperuma G. Emotional intelligence, perceived stress and academic performance of Sri Lankan medical undergraduates. BMC Med Educ 2017; 17:41. [CrossRef]

8. Jones K, Mendenhall S, Myers CA. The effects of sex and gender role identity on perceived stress and coping among traditional and nontraditional students. J Am Coll Health 2016; 64:205-213.

9. Deniz ME, Sumer AS. The evaluation of depression, anxiety and stress in university students with different self-compassion levels. Education and Science 2010; 35:115-127.

10. Williams CB, Galanter M, Dermatis H, Schwartz V. The importance of hopelessness among university students seeking psychiatric counseling. Psychiatr Q 2008; 79:311-319. [CrossRef]

11. Dixon WA, Heppner PP, Burnett JW, Lips BJ. Hopelessness and stress: evidence for an interactive model of depression. Cognit Ther Res 1993; 17:39-52. [CrossRef]

12. Beck AT, Weissman A, Lester D, Trexler L. The measurement of pessimism: the hopelessness scale. J Consult Clin Psychol 1974; 42:861-865. [CrossRef]

13. Abramson LY, Metalsky GI, Alloy LB. Hopelessness depression: a theory-based subtype of depression. Psychol Rev 1989; 96:358372. [CrossRef]

14. O’Connor RC, Sheey NP. Understanding Suicidal Behaviour. Leicester: BPS Books, 2000. 
15. Kleiman EM, Liu RT, Riskind JH, Hamilton JL. Depression as a mediator of negative cognitive style and hopelessness in stress generation. Br J Psychol 2015; 106:68-83. [CrossRef]

16. Dennis JP, Vander Wal JSV. The Cognitive Flexibility Inventory: instrument development and estimates of reliability and validity. Cognit Ther Res 2010; 34:241-253. [CrossRef]

17. Martin MM, Rubin RB. A new measure of cognitive flexibility. Psychol Rep 1995; 76:623-626. [CrossRef]

18. Canas JJ, Fajardo I, Salmeron L. Cognitive flexibility: In Karwowski W (editor). International Encyclopedia of Ergonomics and Human Factors. Second Ed., Boca Raton FL: CRC Press, 2006, vol. 1:297-301.

19. Martin M, Anderson C. The Cognitive Flexibility Scale: three validity studies. Communication Reports 1998; 11:1-9. [CrossRef]

20. Martin M, Anderson CM, Thweatt KS. Aggressive communication traits and their relationships with the Cognitive Flexibility Scale and the Communication Flexibility Scale. J Soc Behav Pers 1998; 13:531-540.

21. Koesten J, Schrodt P, Ford DJ. Cognitive flexibility as a mediator of family communication environments and young adults' wellbeing. Health Commun 2009; 24:82-94. [CrossRef]

22. Gabrys RL, Tabri N, Anisman H, Matheson K. Cognitive control and flexibility in the context of stress and depressive symptoms: The Cognitive Control and Flexibility Questionnaire. Front Psychol 2018; 9: 2219. [CrossRef]

23. Liao KYH, Wei M. Intolerance of uncertainty, depression, and anxiety: the moderating and mediating roles of rumination. J Clin Psychol 2011; 67:1220-1239. [CrossRef]

24. Johnco C, Wuthrich V, Rapee RM. The influence of cognitive flexibility on treatment outcome and cognitive restructuring skill acquisition during cognitive behavioural treatment for anxiety and depression in older adults: Results of a pilot study. Behav Res Ther 2014; 57:55-64. [CrossRef]

25. Yu J, Lee TM. Cognitive flexibility and changes in hopelessness across time: a moderation hypothesis. Appl Neuropsychol Adult 2017; 24:404-409. [CrossRef]

26. Schotte DE, Clum GA. Suicide ideation in a college population: a test of a model. J Consult Clin Psychol 1982; 50:690-696. [CrossRef]

27. Valderrama J. Stress and suicidal behavior: a cognitive, behavioral, and biological integrative approach. Postgraduate Thesis, City University of New York, Graduate Faculty in Psychology, New York, 2016.

28. Greco V, Roger D. Uncertainty, stress, and health. Pers Individ Dif 2003; 34:1057-1068. [CrossRef]

29. Buhr K, Dugas MJ. The role of fear of anxiety and intolerance of uncertainty in worry: an experimental manipulation. Behav Res Ther 2009; 47:215-223. [CrossRef]

30. Zlomke KR, Jeter KM. Stress and worry: examining intolerance of uncertainty's moderating effect. Anxiety Stress Coping 2014; 27:202-215. [CrossRef]

31. Fergus TA, Bardeen JR, Wu KD. Intolerance of uncertainty and uncertainty-related attentional biases: evidence of facilitated engagement or disengagement difficulty? Cognit Ther Res 2013; 37:735-741. [CrossRef]
32. Buhr K, Dugas MJ. The Intolerance of Uncertainty Scale: psychometric properties of the English version. Behav Res Ther 2002; 40:931-945. [CrossRef]

33. Holaway RM, Heimberg RG, Coles ME. A comparison of intolerance of uncertainty in analogue obsessive-compulsive disorder and generalized anxiety disorder. J Anxiety Disord 2006; 20:158-174. [CrossRef]

34. Dugas MJ, Hedayati M, Karavidas A, Buhr K, Francis K, Phillips NA. Intolerance of uncertainty and information processing: evidence of biased recall and interpretations. Cognit Ther Res 2005; 29:57-70. [CrossRef]

35. Yanar M. The evaluation of the relationship between intolerance of uncertainty and hopeless and depression level of the patient and his/her relatives in the waiting process of organ transplantation. Postgraduate Thesis, Istanbul Medipol University, Health Sciences Institute, 2015. (Turkish)

36. Yook K, Kim KH, Suh SY, Lee KS. Intolerance of uncertainty, worry, and rumination in major depressive disorder and generalized anxiety disorder. J Anxiety Disord 2010; 24:623-628.

37. Lieberman L, Gorka SM, Sarapas C, Shankman SA. Cognitive flexibility mediates the relation between intolerance of uncertainty and safety signal responding in those with panic disorder. Cogn Emot 2016; 30:1495-1503. [CrossRef]

38. Ozturk O. Mediator role of cognitive flexibility and intolerance of uncertainty in relationship which between suicide probability and family functionality. Postgraduate Thesis, Ankara University, Social Sciences Institute, Ankara, 2013. (Turkish)

39. Cohen L, Manion L, Morrison K. Research Methods in Education. Seventh ed., Abingdon: Routledge, 2011.

40. Seber G, Dilbaz N, Kaptanoglu C, Tekin D. Hopelessness Scale: validity and reliability. Kriz Dergisi 1993; 1:139-142. (Turkish)

41. Durak A, Palabiyikoglu R. A validity study for the Beck Hopelessness Scale. Kriz Dergisi 2006; 2: 311-319. (Turkish)

42. Gulum IV, Dag I. The Turkish adaptation, validity and reliability study of the Repetitive Thinking Questionnaire and the Cognitive Flexibility Inventory. Anadolu Psikiyatri Derg 2012; 13:216-223. (Turkish)

43. Dogan-Lacin BG. Predictive roles of self-efficacy and coping strategies in cognitive flexibility among university students. Postgraduate Thesis, Ankara, Ankara University, Educational Sciences, 2015. (Turkish)

44. Freeston MH, Rheaume J, Letarte H, Dugas MJ, Ladouceur R. Why do people worry? Pers Individ Dif 1994; 17:791-802. [CrossRef]

45. Sari S, Dag D. Turkish adaptation and validity and reliability study of the Intolerance of Uncertainty Scale, Why Worry-II Scale, and Consequences of Worrying Scale. Anadolu Psikiyatri Derg 2009; 10:261-270. (Turkish)

46. Yerlikaya EE, Inanc B. The psychometric properties of the Turkish translation of Perceived Stress Scale. Ninth National Psychological Counseling and Guidance Congress, 2007. (Turkish)

47. Tabachnick BG, Fidell LS. Using Multivariate Statistics. Sixth Ed. Boston: Pearson, 2013. 
48. Preacher K, Hayes A. Asymptotic and resampling strategies for assessing and comparing indirect effects in multiple mediator models. Behav Res Methods 2008; 40:879-891. [CrossRef]

49. Vanderweele TJ. Explanation in Causal Inference: Methods for Mediation and Interaction. Oxford: Oxford University Press, 2015

50. Hayes AF. PROCESS: A Versatile Computational Tool for Observed Variable Mediation, Moderation, and Conditional Process Modeling [White paper], 2012. http://www.afhayes.com/ public/process2012.pdf. Accessed August 16, 2019.

51. Hayes AF. Introduction to Mediation, Moderation, and Conditional Process Analysis: A Regression-Based Approach. Second ed., New York: Guilford Press, 2017.

52. Littlewood DL, Gooding PA, Panagioti M, Kyle SD. Nightmares and suicide in posttraumatic stress disorder: the mediating role of defeat, entrapment, and hopelessness. J Clin Sleep Med 2016; 12:393-399. [CrossRef]

53. Boffa JW, Stanley IH, Smith LJ, Mathes BM, Tran JK, Buser SJ, Schmidt NB, Vujanovic AA. Posttraumatic stress disorder symptoms and suicide risk in male firefighters: the mediating role of anxiety sensitivity. J Nerv Ment Dis 2018; 206:179-186.

54. Frankl VE. From Death-Camp to Existentialism: A Psychiatrist's Path to a New Therapy. Beacon Hill: Beacon Press, 1959.

55. Peleg G, Barak O, Harel Y, Rochberg J, Hoofien D. Hope, dispositional optimism and severity of depression following traumatic brain injury. Brain Inj 2009; 23:800-808. [CrossRef]
56. Dhanalakshmi D. Perceived stress, cognitive distortion, sense of coherence and health among college students. Indian Journal of Health and Wellbeing (IJHW) 2015; 6:287-291.

57. Heisel MJ, Flett GL, Hewitt PL. Social hopelessness and college student suicide ideation. Arch Suicide Res 2003; 7:221-235. [CrossRef]

58. Snyder CR, LaPointe AB, Crowson JJ, Early S. Preferences of high- and low-hope people for self-referential input. Cogn Emot 1998; 12:807-823. [CrossRef]

59. Dugas MJ, Gosselin P, Ladouceur R. Intolerance of uncertainty and worry: investigating specificity in a nonclinical sample. Cognit Ther Res 2001; 25:551-558. [CrossRef]

60. Lee JK, Orsillo SM. Investigating cognitive flexibility as a potential mechanism of mindfulness in Generalized Anxiety Disorder. J Behav Ther Exp Psychiatry 2014; 45:208-216. [CrossRef]

61. Counsell A, Furtado M, Iorio C, Anand L, Canzonieri A, Fine A, Fotinos K, Epstein I, Katzman MA. Intolerance of uncertainty, social anxiety, and generalized anxiety: differences by diagnosis and symptoms. Psychiatry Res 2017; 252:63-69. [CrossRef]

62. Lally J, Cantillon P. Uncertainty and ambiguity and their association with psychological distress in medical students. Acad Psychiatry 2014; 38:339-344. [CrossRef]

63. Chen CY, Hong RY. Intolerance of uncertainty moderates the relation between negative life events and anxiety. Pers Individ Dif 2010; 49:49-53. [CrossRef] 